\title{
Questionnaire-based detection of immune- related adverse events in cancer patients treated with PD-1/PD-L1 immune checkpoint inhibitors
}

Luisa Maria Griewing ${ }^{1,2}$, Claudia Schweizer ${ }^{1,2}$, Philipp Schubert ${ }^{1,2}$, Sandra Rutzner ${ }^{1,2}$, Markus Eckstein ${ }^{2,3}$, Benjamin Frey ${ }^{1,2}$, Marlen Haderlein ${ }^{1,2}$, Thomas Weissmann ${ }^{1,2}$, Sabine Semrau ${ }^{1,2}$, Antoniu-Oreste Gostian²,4, Sarina K. Müller 2,4, Maximilian Traxdorf ${ }^{2,4}$, Heinrich Iro ${ }^{2,4}$, Jian-Guo Zhou ${ }^{1,2,5}$, Udo S. Gaipl ${ }^{1,2}$, Rainer Fietkau ${ }^{1,2}$ and Markus Hecht ${ }^{1,2^{*}}$

\begin{abstract}
Background: Immune checkpoint inhibitors (ICI) have become standard treatment in different tumor entities. However, safe treatment with ICI targeting the PD-1/PD-L1 axis requires early detection of immune-related adverse events (irAE). There exist different questionnaires of drug manufacturers for the detection of irAE that have not been validated so far.
\end{abstract}

Methods: The prospective non-interventional ST-ICI trial studied treatment with PD-1/PD-L1 ICI alone or combined with radiotherapy. In the current analysis, the detection rate of self-reported irAE with a patient questionnaire containing 41 different questions was compared to clinician-reported irAE.

Results: Between April 2017 and August 2019, a total of 104 patients were prospectively enrolled. NSCLC (44\%) and HNSCC (42\%) were the most frequent tumor entities. A total of 784 questionnaires were collected. A total of 29 irAE were reported by clinicians. The most frequent irAE was hypothyroidism (9\%), followed by skin reactions (5\%), hepatitis (4\%), diarrhea (3\%), and pneumonitis (3\%). Questions that became significantly more often positive at time points of clinician-reported irAE were "weight change", "difficulty to grip things", "bloody or mucous stool" and "insomnia". Self-reported organ-specific questions detected at least 50\% of clinician-reported irAE of gastrointestinal, lung, endocrine, and skin irAE. It was not possible to detect hepatic irAE with the questionnaire.

Conclusion: Questionnaires can help to detect gastrointestinal, lung, endocrine, or skin irAE, but not hepatic irAE. Questions on "weight change" and "insomnia" may help to increase the detection rate of irAE, besides organspecific questions. These results are a valuable contribution to the future development of a specific and practicable questionnaire for early self-reported detection of irAE during ICI therapy in cancer patients.

(Continued on next page)

\footnotetext{
* Correspondence: markus.hecht@uk-erlangen.de

'Department of Radiation Oncology, Universitätsklinikum Erlangen,

Friedrich-Alexander-Universität Erlangen-Nürnberg, Universitätsstraße 27,

91054 Erlangen, Germany

${ }^{2}$ Comprehensive Cancer Center Erlangen-EMN, Erlangen, Germany

Full list of author information is available at the end of the article
} 
(Continued from previous page)

Trial registration: ClinicalTrials.gov, NCT03453892. Registered on 05 March 2018.

Keywords: Immune checkpoint inhibitors, PD-1, Immune-related adverse events, Toxicity, Questionnaire, PD-L1, Side effects, Solid tumors, Patient-reported irAE

\section{Background}

Over the last decade, treatment with immune checkpoint inhibitors (ICI) against programmed cell death protein 1 (PD-1) and one of its ligands PD-L1 have become one of the most promising approaches in the field of cancer therapy. Consequently, their application in oncologic treatment is continuously increasing $[1,2]$. However, despite the advantages of ICI therapy, a valid predictive biomarker that accurately identifies patients who will benefit from ICI treatment has yet to be developed. The expression of PD-L1 on tumor cells and/or immune cells has been identified as one of such immune biomarkers. Nevertheless, the expression of PD-L1 is not stable as it is e.g. up-regulated by radiochemotherapy [3-6]. Also the tumor mutational burden or the intratumoral CD8 cell density may serve as a predictive marker $[7,8]$. The great success of ICI is shadowed by the induction severe immune-related adverse events in some patients. The gastrointestinal, pulmonary, dermatologic, hepatic, and endocrine systems are thereby frequently affected $[1,9,10]$. The ASCO Clinical Practice Guideline Summary presents a system-based toxicity diagnosis and management guideline, which recommends treatments depending on the affected system $[11,12]$. Several studies have shown that the occurrence of immune-related adverse events (irAE) might have a positive influence on tumor treatment response and the survival rate [13-17]. As a result, the onset of irAE represents a potentially beneficial clinical marker for ICI efficacy and should be further evaluated also in this respect. However, the occurrence and frequency of reported adverse events (AE) differ between patient self-reports and diagnoses of the managing clinicians. In this regard, patients tend to report AE more often and earlier. Consequently, it seems appropriate to increase patient self-reports using appropriate questionnaires for timely detection and subsequent therapy of $\mathrm{AE}[18,19]$. Pharmacokinetics of ICI allow dose intervals of up to 6 weeks $[10,20]$. These long dose intervals bear the risk that irAE may be detected late, which impairs patients' safety. Patient selfreports on irAE may help to ensure an early detection of irAE despite these long dose intervals.

There exist different questionnaires of drug manufacturers for the detection of irAE that have not been validated so far. Adapted from these questionnaires an own questionnaire was developed for patients' self-reported detection of irAE. The aim of the current analysis is to compare the patients' self-reported irAE to clinicianreported irAE.

\section{Methods \\ Patients}

Patients with non-melanoma solid tumors and the indication for ICI treatment with either a PD-1 or PD-L1 inhibitor were eligible for the trial. Concomitant radiotherapy was not obligatory. To represent an unselected cohort, there was no restriction concerning baseline Eastern Cooperative Oncology Group (ECOG) performance status, pre-existing diseases, tumor entity, or blood parameters.

\section{Trial design and treatments}

ST-ICI is a prospective non-interventional, nonrandomized trial in tumor patients treated with ICI. Patients receive either immunotherapy in combination with radiotherapy or immunotherapy alone. A secondary endpoint of the current interim analysis is the detection rate of irAE using a newly developed questionnaire. All treatment decisions are made by treating physicians based on clinical standards and national guidelines. Any EMA-approved PD-1 or PD-L1 inhibitor treatment was allowed within the trial. Dose and the treatment indication of the ICI were according to the EMA marketing authorization. Radiotherapy was delivered either as stereotactic radiosurgery or fractionated radiotherapy.

\section{Endpoints and assessments}

The current analyses focus on a secondary endpoint of the ST-ICI trial. In this explorative interim analysis the detection of different irAE with a newly developed 41 item irAE questionnaire is studied (Fig. 1). The questionnaire consists of eight multi-item symptom scales (gastrointestinal, pulmonary, endocrine, skin, hepatic, neurologic, renal, and non-specific). All symptom scales contain several binary response questions ("yes" or "no") to identify specific irAE. Patients were asked to complete the questionnaire for irAE before each administration of the PD-1 or PD-L1 inhibitor, i.e. typically every second or third week beginning with the first administration. Patients had to complete the questionnaire in a written form without support from the medical personal and before the contact to the clinician. The clinician-reported 


\begin{tabular}{|c|c|c|c|}
\hline \multicolumn{3}{|c|}{$\underline{\text { ST-ICI trial: irAE assessment }}$} & \multirow[b]{4}{*}{$\square$ Yes $\square$ No } \\
\hline Last name: & First name: & Birthdate: & \\
\hline E-mail: & Phone: & Date: & \\
\hline A) Gastrointestinal irAE & & \multirow{3}{*}{$\begin{array}{l}\text { 24. Do you suffer from itchiness of the skin? } \\
25 . \text { Have you noticed a deterioration of a previously } \\
\text { diagnosed skin disease? }\end{array}$} & \\
\hline 1. Do you feel unwell? & $\square$ Yes $\square$ No & & \\
\hline 2. Do you have a loss of appetite? & $\square$ Yes $\square$ No & & $\square$ Yes $\square$ No \\
\hline 3. Did you have nausea or vomiting? & $\square$ Yes $\square$ No & E) Hepatic irAE & \\
\hline 4. Are your bowel movements different from usual? & $\square$ Yes $\square$ No & 26. Have you noticed any yellowing of your skin & \\
\hline 5. Do you have nocturnal defecation? & $\square$ Yes $\square$ No & or eyes? & $\square$ Yes $\square$ No \\
\hline 6. Is your stool thin or foul-smelling? & $\square$ Yes $\square$ No & 27. Do you suffer from painful upper right abdomen? & $\square$ Yes $\square$ No \\
\hline $\begin{array}{l}\text { 7. Do you have pain with defecation? } \\
\text { 8. Are you having abdominal cramps? }\end{array}$ & $\begin{array}{l}\square \text { Yes } \square \text { No } \\
\square \text { Yes } \square \text { No }\end{array}$ & F) Neurologic irAE & \\
\hline 9. Do you have abdominal pain? & $\square$ Yes $\square$ No & \multirow{2}{*}{$\begin{array}{l}\text { 28. Do you have a headache? } \\
\text { 29. Do you feel dizzy? }\end{array}$} & $\square$ Yes $\square$ No \\
\hline 10. Do you have blood or mucous stool? & $\square$ Yes $\square$ No & & $\square$ Yes $\square$ No \\
\hline B) Pulmonary irAE & & \multirow{2}{*}{$\begin{array}{l}\text { 30. Have you noticed any change in your vision? } \\
\text { 31. Is it difficult to grip things or do things fall out }\end{array}$} & $\square$ Yes $\square$ No \\
\hline 11. Do you have increased coughing? & $\square$ Yes $\square$ No & & $\square$ Yes $\square$ No \\
\hline 12. Do you have mucous sputum? & $\square$ Yes $\square$ No & of your hand & \\
\hline 13. Do you suffer from shortness of breath? & $\square$ Yes $\square$ No & $\begin{array}{l}\text { 32. Have you noticed any tingling or numbness in } \\
\text { your hands or feet? }\end{array}$ & $\square$ Yes $\square$ No \\
\hline 14. Are you having difficulty breathing? & $\square$ Yes $\square$ No & 33. Do you suffer from impaired vision? & $\square$ Yes $\square$ No \\
\hline C) Endocrine irAE & & G) Renal irAE & \\
\hline 15. Do you suffer from insomnia? & $\square$ Yes $\square$ No & & $\square$ Yes $\square$ No \\
\hline 16. Do you suffer from fatigue? & $\square$ Yes $\square$ No & 35. Do you have blood in your urine? & $\square$ Yes $\square$ No \\
\hline 17. Do you suffer from exhaustion? & $\square$ Yes $\square$ No & & $\square$ Yes $\square$ No \\
\hline 18. Do you feel dizzy? & $\square$ Yes $\square$ No & H) Non-specific irAE & \\
\hline $\begin{array}{l}\text { 19. Are you excessively thirsty? } \\
\text { 20. Have you noticed changes in libido (sex drive)? }\end{array}$ & $\begin{array}{l}\square \text { Yes } \square \text { No } \\
\square \text { Yes } \square \text { No }\end{array}$ & 37. Are you able to perform the usual activities? & $\square$ Yes $\square$ No \\
\hline 21. Are you suffering from palpitations? & $\square$ Yes $\square$ No & 38. Do you have a fever? & $\square$ Yes $\square$ No \\
\hline D) Skin irAE & & 39. Do you have joint pain? & $\square$ Yes $\square$ No \\
\hline & & & $\square$ Yes $\square$ No \\
\hline 22. Have you noticed increased hair loss? & $\square$ Yes $\square$ No & \multirow{2}{*}{$\begin{array}{l}\text { 41. Do you suffer from psychological changes; } \\
\text { for example: depressed or irritable? }\end{array}$} & \\
\hline 23. Do you have a skin rash? & $\square$ Yes $\square$ No & & $\square$ Yes $\square$ No \\
\hline
\end{tabular}

irAE were assessed routinely before every administration of the drug and in case of new symptoms. The questionnaire was not visible to the clinician. The clinicianreported irAE were classified according to the Common Terminology Criteria of Adverse Events (CTCAE), version 5.0.

The primary objective of the presented work was to investigate whether irAE can be detected by organspecific questions (e.g. diarrhea by gastrointestinal questions). Furthermore, questions concerning any irAE have been analyzed independently from their specific irAE, to identify general screening-questions for any irAE. This should help to identify appropriate questions for the development of a specific questionnaire on irAE, which can enter a future questionnaire validation process.

\section{Trial oversight}

The registration of the ST-ICI trial is allocated in Clinical Trails.gov (identifier: NCT03453892). The leading institutional review board at the Friedrich-AlexanderUniversität Erlangen-Nürnberg approved the study (number: 2_17 B). The written informed consent of all patients has been obtained. The study had no external funding. All methods were performed in accordance with the relevant guidelines and the Declaration of Helsinki.

\section{Statistical analysis}

Due to the very low prevalence of irAE compared to the number of questionnaires the frequency of positively answered questions at time points of clinician reported irAE will be presented descriptively. Due to this imbalance of the high number of questionnaires and low number of irAE classical parameters as sensitivity, specificity, positive and negative predictive values were waived. It is the aim of this explorative analysis of this prospective trial to identify appropriate questions for the development of a specific questionnaire that can enter a classical validation process. IBM SPSS Statistics version 24 was used for performing all statistical tests. Fisher's exact test was used to study differences in the frequency of positively answered questions in the subgroups with and without irAE. $P$-values below 0.05 level are expected to be statistically significant. The statistical analysis was done for all irAE, the types of irAE were not analyzed separately. 


\section{Results}

\section{Patients and treatment}

The ST-ICI trial registered 104 patients between April 2017 and August 2019. Baseline characteristics of the patients are given in Table 1 . The median age was 66 years and $73 \%$ were male. Thirty-six patients (35\%) had PD-L1 negative tumors (PD-L1 $<1 \%$ ). All patients received immunotherapy with a PD-1 or PD-L1 inhibitor. Out of these, 50 patients (48\%) received additional radiotherapy within 30 days before or after an application of immunotherapy. Detailed information on radiotherapy has been previously reported [21]. Non-small cell lung cancer (NSCLC, 44\%) and head and neck squamous cell cancer (HNSCC, 42\%) were the most frequent tumor entities. The remaining tumor entities in the cohort represented bladder cancer (5\%), oesophageal cancer (4\%), and other tumor entities (5\%). The most frequent comorbidities were arterial hypertonia (33\%) followed by other cardiovascular comorbidities (29\%), diabetes mellitus (19\%), and COPD (17\%). Two patients with autoimmune diseases were included (2\%). The majority of patients received the ICI nivolumab (64\%) followed by pembrolizumab (23\%) and durvalumab (9\%). Immunotherapy was given in a palliative setting in 92 patients $(88 \%)$ and an adjuvant setting in 12 patients (12\%). The patients with palliative treatment included 15 patients (14\%) with local tumor recurrence only and 77 patients (74\%) with distant metastases, respectively. The median follow-up time was 8.3 months, whereas questionnairebased irAE assessment was discontinued at the end of immunotherapy.

\section{Incidence and grades of irAE}

Twenty-nine out of one hundred four surveyed patients developed any irAE (Table 2). The median time from first drug administration to the endpoint clinicianreported irAE was 2.3 months. Hypothyroidism was the most frequent one (9\%), followed by skin reactions $(5 \%)$, hepatitis (4\%), diarrhea (3\%), pneumonitis (3\%), and other irAE (5\%). According to CTCAE 25 patients (24\%) were classified to grade $1-2$ reactions while four patients (4\%) developed grade 3 irAE. No grade 4 and 5 events were observed. All cases of hypothyroidism and hepatitis were confirmed by laboratory tests, skin reactions were evaluated clinically, all cases of pneumonitis were confirmed by CT scan. Colonoscopy in case of diarrhoea was not mandatory. In five patients irAE led to immunotherapy treatment interruption and in six patients to permanent discontinuation. In the two patients with pre-existing autoimmune diseases, one patient with psoriasis experienced a disease flare and one patient with Hashimoto's thyroiditis in the hypothyroid stage experienced no irAE. As mentioned above, some patients received radiotherapy in addition to immunotherapy. In order to clarify that irAE in these patients are no local radiotherapy effects, these cases are summarized in supplementary Table 1.

\section{Patient irAE screening questionnaire}

A total of 784 questionnaires were collected. Out of the 104 surveyed patients, 96 patients (92\%) completed at least one questionnaire. The median number of completed questionnaires per patient was 6 (range 0-40). Figure $2 \mathrm{a}$-h depicts the percentage for each question that was positively answered separately for patients with no current clinician-reported irAE, for patients with current clinician-reported irAE, and for those with current clinician-reported irAE related to the organ-specific panel.

Clinician-reported gastrointestinal irAE were detected by different questions at a rate of $\geq 50 \%$ as "feeling unwell", "nausea or vomiting", "differing bowel movements", "nocturnal defecation", "thin or foul-smelling stool", "abdominal pain" and "bloody or mucous stool" (Fig. 2a). Questions on "loss of appetite", "painful defecation" or "abdominal cramps" did not correlate with gastrointestinal irAE.

Clinician-reported pulmonary irAE were detected at a rate of $\geq 50 \%$ by the questions "shortness of breath" and "difficulty in breathing" (Fig. 2b). Patients with pulmonary irAE, i.e. pneumonitis, did not report suffering from "increased coughing" and "mucous sputum".

Clinician-reported endocrine irAE were identified in at least $\geq 50 \%$ of cases by the question on "insomnia". The question on "fatigue" increased in endocrine irAE to $70 \%$, whereas it was also answered positively in $49 \%$ of patients without irAE (Fig. 2c). Questions on "exhaustion", "dizziness", "excessive thirst", "libido changes" or "palpitations" did not identify endocrine irAE.

Clinician-reported skin irAE were detected at a rate of $\geq 50 \%$ by the questions "skin rash", "itchiness" and "deterioration of skin diseases", whereas the question "hair loss" was not increased in skin irAE (Fig. 2d). Hepatic irAE were not detected, neither by the question "yellowing of skin or eyes" nor the question on "painful upper right abdomen" (Fig. 2e). The questionnaire also contained a neurologic and renal question panel, whereas no neurologic irAE (Fig. 2f) and no renal irAE (Fig. 2g) appeared. Several non-specific questions were asked for the general detection of any irAE or rare irAE (Fig. 2h).

Besides the aim to detect irAE organ-specific with this questionnaire, also general questions for the detection of any irAE were searched. Generally, the positive rate of several questions increased in patients with clinicianreported irAE, especially in the gastrointestinal, endocrine, and neurologic question panel. Patients who developed any clinician-reported irAE complained more 
Table 1 Patient characteristics of the ST-ICl cohort

\begin{tabular}{|c|c|}
\hline Patient characteristics & $\begin{array}{l}\text { All patients } \\
n=104(\%)\end{array}$ \\
\hline \multicolumn{2}{|l|}{ Sex } \\
\hline Male & $76(73)$ \\
\hline Female & $28(27)$ \\
\hline Median age \pm SD (years) & $66 \pm 10.2$ \\
\hline \multicolumn{2}{|l|}{ Treatment arm } \\
\hline IT-RT & $50(48)$ \\
\hline IT-only & $54(52)$ \\
\hline \multicolumn{2}{|c|}{ Location of radiotherapy $\mathrm{y}^{\mathrm{a}}(n=50)$} \\
\hline Lung & 17 (34) \\
\hline CNS & $10(20)$ \\
\hline Bone & $5(10)$ \\
\hline Other & $18(36)$ \\
\hline \multicolumn{2}{|l|}{ PD-L1 tumor cells } \\
\hline$<1 \%$ & 36 (35) \\
\hline $1-49 \%$ & $33(32)$ \\
\hline$\geq 50 \%$ & $32(31)$ \\
\hline Unknown & $3(3)$ \\
\hline Brain metastases & $24(23)$ \\
\hline \multicolumn{2}{|l|}{ Tumor entity } \\
\hline NSCLC & $46(44)$ \\
\hline HNSCC & $44(42)$ \\
\hline Bladder cancer & $5(5)$ \\
\hline Oesophageal cancer & $4(4)$ \\
\hline Other & $5(5)$ \\
\hline \multicolumn{2}{|l|}{ Number of previous treatments } \\
\hline $0-1$ & $61(59)$ \\
\hline$\geq 2$ & $43(41)$ \\
\hline \multicolumn{2}{|l|}{ Disease stage } \\
\hline Adjuvant setting & $12(12)$ \\
\hline Palliative setting & $92(88)$ \\
\hline local tumor recurrence & $15(14)$ \\
\hline distant metastases & $77(74)$ \\
\hline \multicolumn{2}{|l|}{ Drug } \\
\hline Nivolumab & $66(64)$ \\
\hline Pembrolizumab & $24(23)$ \\
\hline Durvalumab & $9(9)$ \\
\hline Other & $5(5)$ \\
\hline Concomitant chemotherapy & $6(6)$ \\
\hline \multicolumn{2}{|l|}{ Comorbidity $^{\mathrm{b}}(n=199)$} \\
\hline Arterial hypertonia & $34(33)$ \\
\hline Cardiovascular comorbidity & $30(29)$ \\
\hline Diabetes & $20(19)$ \\
\hline COPD & 18 (17) \\
\hline Autoimmune disease & $2(2)$ \\
\hline Other & $87(84)$ \\
\hline None & $8(8)$ \\
\hline
\end{tabular}

anly radiotherapy within 30 days before or after first administration of $\mathrm{ICI}$

${ }^{b}$ Multiple co-morbidities per patient possible

SD Standard deviation, IT Immunotherapy, RT Radiotherapy, CNS Central nervous system, PD-L1 Programmed death ligand, HNSCC Head and neck squamous cell carcinoma, NSCLC Non small cell lung carcinoma 
often about "weight change" $(p=0.041)$, "difficulty to grip things" ( $p=0.036)$, bloody or mucous stool" ( $p=$ $0.039)$, and "insomnia" ( $p=0.012)$ in the self-reporting questionnaire (Fig. 2).

\section{Discussion}

ICI are nowadays frequently used in the treatment of cancer and are increasingly integrated in multimodal approaches with chemotherapy or radiotherapy in current clinical trials [22]. However, ICI represent a rather novel therapy that goes along with a new type of potentially life-threatening irAE. As described, they may affect any organ system $[1,23]$. Consequently, accompanying irAE should be detected and treated early. In this regard, questionnaires are a potentially easy-to-handle and beneficial tool for the timely detection and sufficient treatment of irAE [10, 20].

Various clinical trials identified differences between severity and frequency when $\mathrm{AE}$ are reported and measured by patients themselves or by supervising clinicians. Frequently, patients report their symptoms earlier and more often. Their reporting is better associated with the daily health status, whereas the clinical CTCAE assessment predicts unfavorable clinical outcomes [18, 19, 24]. This led to the development of the PRO CTCAE to capture symptomatic adverse events by patient self-report in cancer clinical trials $[25,26]$. The PRO-CTCAE is very comprehensive including 124 items representing 78 symptomatic toxicities.

The presented work used our newly designed binary response questionnaire focusing on the most affected organ systems by ICI, i.e. gastrointestinal, lung, endocrine, skin, liver, neurologic, and renal. The questions are based on questionnaires provided by the manufacturers of ICI. The final questionnaire contains 41 binary questions.

Dermal side effects as rash, itchiness, and vitiligo are frequently mentioned during PD-1/PD-L1 inhibitor therapy $[23,27,28]$. In the ST-ICI study we observed patients noticing skin changes (especially skin rash) by

Table 2 Immune-related adverse events

\begin{tabular}{llll}
\hline irAE $^{\text {a }}$ & Any Grade & Grade 1-2 & Grade 3 \\
& $\boldsymbol{n = 1 0 4}(\%)$ & $\boldsymbol{n = 1 0 4}(\%)$ & $\boldsymbol{n}=\mathbf{1 0 4}(\%)$ \\
\hline Any irAE & $29(28)$ & $25(24)$ & $4(4)$ \\
Hypothyroidism & $9(9)$ & $9(9)$ & $0(0)$ \\
Skin reaction & $5(5)$ & $5(5)$ & $0(0)$ \\
Hepatitis & $4(4)$ & $1(1)$ & $3(3)$ \\
Diarrhea & $3(3)$ & $3(3)$ & $0(0)$ \\
Pneumonitis & $3(3)$ & $3(3)$ & $0(0)$ \\
Other & $5(5)$ & $4(4)$ & $1(1)$ \\
\hline
\end{tabular}

${ }_{\text {irAE Immune-related adverse event. No grade } 4 \text { and } 5 \text { events were observed }}$ themselves, which they documented in the questionnaires. The most common gastrointestinal complications are diarrhea and colitis. An increasing number of positive answers to the different questions confirmed complications as diarrhea and colitis. It can be assumed that gastrointestinal irAE can be detected easily with questionnaires as well. Endocrine irAE include thyroid dysfunction, hypophysitis, diabetes mellitus, and primary adrenal insufficiency. Concerning thyroid dysfunction, hypothyroidism is the most common one showing unspecific symptoms as fatigue [29]. However, fatigue is a very frequent and non-specific symptom of cancer patients but did not prove as an appropriate indicator of endocrine irAE. Interestingly, patients with endocrine irAE frequently mentioned the complaint insomnia. Hepatitis is the most frequent hepatic irAE [23, 30]. Here the questionnaire could not detect any difference from the baseline, which is in line with our expectations as hepatitis can be detected early by elevation of transaminases and is clinically often asymptomatic or associated with non-specific symptoms such as weakness, fatigue, nausea, or vomiting [31]. Pneumonitis remains a rare but concerning complication of ICI therapy. It is often detected with dyspnea or other pulmonary symptoms [32, 33]. Patients who developed pneumonitis in our study reported shortness of breath and difficulty in breathing. Thus, pneumonitis can also be detected by questionnaires. Neurologic and renal irAE are rare, but severe complications of immunotherapy. Most of the renal irAE are presented as acute interstitial nephritis $[34,35]$. In the ST-ICI study no patient developed neurological and renal irAE. Thus, the questions concerning neurological and renal irAE could only be examined for any other side effects. In total, the data from the questionnaire of the ST-ICI trial shows a relation between the patient-reported and clinician-reported irAE. Several questions indicate a specific irAE.

Besides the detection of an organ-specific irAE, general screening questions for irAE would be helpful to monitor patients with long dose intervals of ICI. Within the ST-ICI questionnaire, patients with irAE answered the questions on "weight change", "difficulty to grip things", "bloody or mucous stool" and "insomnia" significantly more often positive. Other than "bloody or mucopurulent stool" associated with colitis, it is not clear why the other responses became positive in the case of irAE. One could speculate that transient short-term hyperthyroidism could cause the insomnia. Furthermore, hyperor hypothyroidism could be causative for the weight changes. These questions might serve as screening questions for irAE in future questionnaires.

Based on our results, future questionnaires can be reduced to one question per organ system as the inclusion of multiple questions per organ system did not increase 


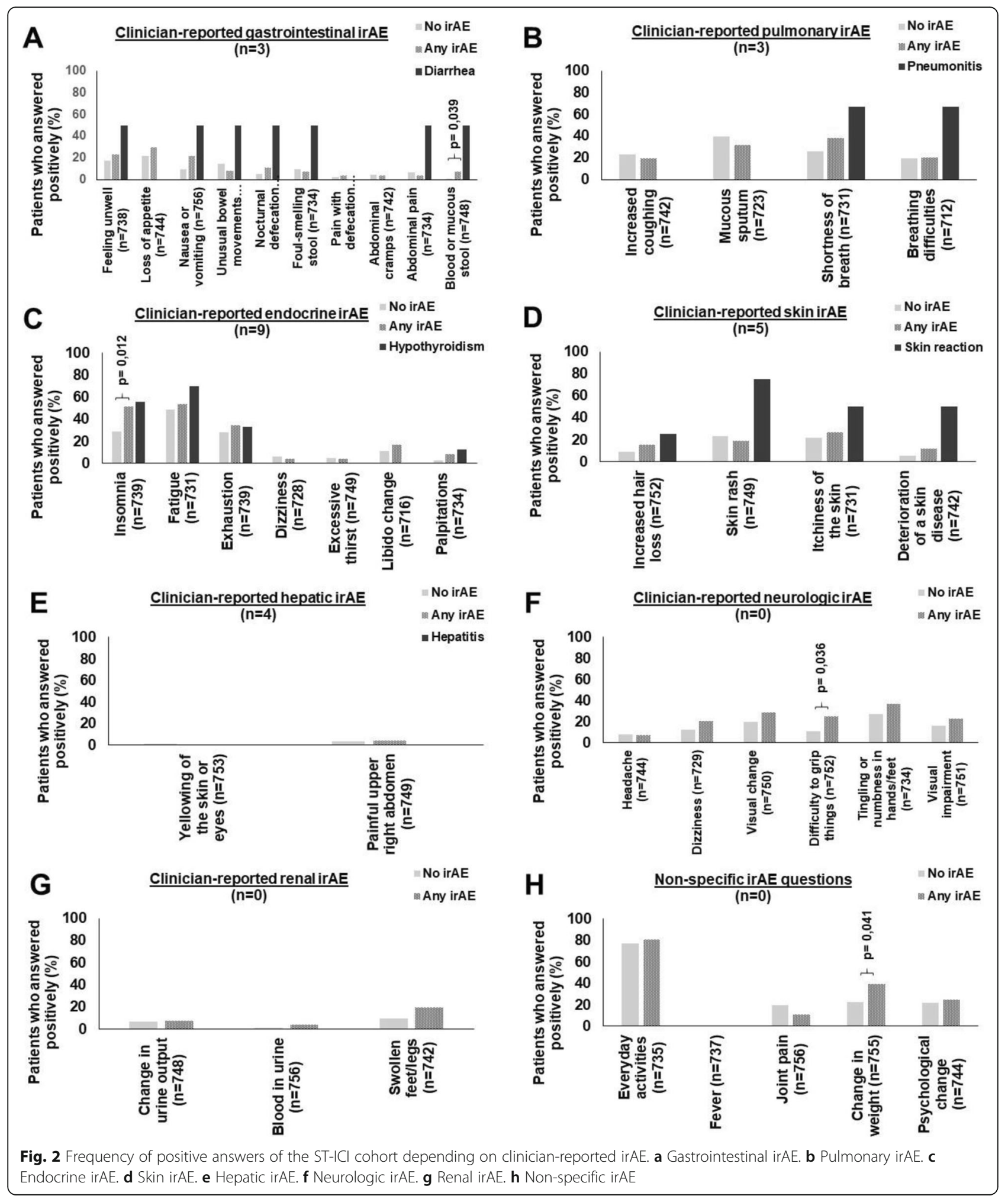

the detection rate. In addition non-specific questions as "weight change" or "insomnia" might increase the detection rate of irAE.
A potential bias of the ST-ICI trial may be that patients filled in the questionnaire before their contact with the physician. This may have encouraged them to 
report their symptoms to the physician and increased the correlation between patient- and clinician-reported irAE. Clinician-reported irAE were diagnosed according to clinical standards, there was no standardized diagnostic workup. A further limitation of the ST-ICI cohort is that the used questionnaire was adapted from questionnaires of drug manufacturers and has not been validated before. However, there exist no validated questionnaires on self-reported irAE detection so far. Thus, the presented analysis is a first step to identify appropriate questions for the development of a specific irAE questionnaire that can enter a validation process. Due to the high number of collected questionnaires and low number of irAE the results are presented only descriptively. In the current trial the calculation of sensitivity, specificity, and positive/negative predictive value was not the aim of the trial and is not possible within this study design. The number of included patients and clinicianreported irAE is too low for such analyses. Altogether 29 irAEs were reported, including three cases of diarrhoea. This underrepresentation of the irAE diarrhoea might also be a consequence of the low patient number. The mixed patient cohort including several tumor entities might be rated as a further limitation. However, the development of irAE does not depend on the treated tumor entity. The inclusion of different tumor entities is probably a strength as in a patient cohort with a single tumor entity, special organ-specific symptoms might be overrepresented (e.g. breathing problems in NSCLC). The major strength of the ST-ICI trial is its prospective design. Furthermore, the collection of a high number of questionnaires $(n=784)$ and close monitoring of patients is in favor of the presented results. The extremely high rate of completed questionnaires (92\% of included patients) is unique. This also proves the suitability of this questionnaire for daily routine use. As mentioned above, the identification of irAE is essential for the patients' safety. There exists a mild correlation between a reduction of quality of life during radiochemotherapy and prolonged survival, which is probably a marker for treatment intensity [36]. However, in case of the occurrence of irAE, ICI treatment frequently has to be stopped and irAE management has to be started. In contrast to past assumptions, treatment interruptions and glucocorticoid use for irAE management are no obstacle for the treatment success. Recent analyses of our ST-ICI trial and other trials indicate that patients with irAE have a superior prognosis compared to patients without irAE [13-17].

\section{Conclusions}

Questionnaires can help to detect gastrointestinal, lung, endocrine, or skin irAE, but not hepatic irAE. Questions on "weight change" and "insomnia" may help to increase the detection rate of irAE, besides organ-specific questions. These results are a valuable contribution to the future development of a specific and practicable questionnaire for early self-reported detection of irAE during ICI therapy in cancer patients.

\section{Abbreviations}

ASCO: American Society of Clinical Oncology; CTCAE: Common Terminology Criteria of Adverse Events; ECOG: Eastern Cooperative Oncology Group; EMA: European Medicines Agency; HNSCC: Head and neck squamous cell cancer; ICI: Immune checkpoint inhibitors; irAE: Immune-related adverse events; NSCLC: Non-small cell lung cancer; PD-1: Programmed cell death 1 protein; PD-L1: Programmed cell death ligand 1; PRO: Patient reported outcome

\section{Supplementary Information}

The online version contains supplementary material available at https://doi. org/10.1186/s12885-021-08006-0.

Additional file 1: Supplementary Table 1. Location of radiotherapy in patients with irAE.

\section{Acknowledgements}

The present work was performed by the first author Luisa Maria Griewing in fulfillment of the requirements for obtaining the degree "Dr. med.".

\section{Authors' contributions}

Guarantor of integrity of the entire study: R.F. Study concepts and design: R.F., M.He., U.S.G., B.F., S.R., M.E. Literature research: L.M.G., M.He. Clinical Studies (recruitment of patients): M. He, C.S., P.S., M.Ha., T.W., S.S., A.O.G., S.K.M., M.T., H.I. Data analysis: L.M.G, M.He., R.F., J.G.Z. Statistical analysis: L.M.G, M.He. Manuscript preparation: L.M.G. Manuscript editing: M.He., A.O.G. All authors approved the submitted version and agreed both to be personally accountable for the author's own contributions and to ensure that questions related to the accuracy or integrity of any part of the work, even ones in which the author was not personally involved, are appropriately investigated, resolved, and the resolution documented in the literature.

\section{Funding}

The study had no external funding. Open Access funding enabled and organized by Projekt DEAL.

\section{Availability of data and materials}

The data that support the findings of this study are available from the corresponding author upon reasonable request.

\section{Declarations}

\section{Ethics approval and consent to participate}

The leading institutional review board at the Friedrich-Alexander-Universität Erlangen-Nürnberg approved the study (number: 2_17 B). The written informed consent of all patients has been obtained. All methods were performed in accordance with the relevant guidelines and the Declaration of Helsinki.

\section{Consent for publication \\ Not applicable.}

\section{Competing interests}

S.R. conflict of interest with AstraZeneca (research funding); MSD (research funding). M.E. conflict of interest with Diaceutics (employment, honoraria, advisory role, speakers' bureau, travel expenses); AstraZeneca (honoraria, advisory role, speakers' bureau, travel expenses); Roche (honoraria, travel expenses); MSD (honoraria, speakers' bureau); GenomicHealth (honoraria, advisory role, speakers bureau, travel expenses); Astellas (honoraria, speakers' bureau); Janssen-Cilag (honoraria, advisory role, research funding, travel expenses); Stratifyer (research funding, patents). S.S. conflict of interest with Strycker (stock); Varian (stock); Abbot (stock); Crispr Techn. (stock); Pfitzer 
(stock); Merck Serono (stock); Symrise (stock); Ortho (honoraria, advisory role, speakers' bureau, research funding, travel expenses); PharmaMar (speakers' bureau, travel expenses); Haema (speakers' bureau). U.S.G. conflict of interest with AstraZeneca (advisory role, research funding); BMS (advisory role); MSD (research funding); Sennewald Medizintechnik (travel expenses). R.F. conflict of interest with MSD (honoraria, advisory role, research funding, travel expenses); Fresenius (honoraria); BrainLab (honoraria); AstraZeneca (honoraria, advisory role, research funding, travel expenses); Merck Serono (advisory role, research funding, travel expenses); Novocure (advisory role, speakers' bureau, research funding); Sennewald (speakers' bureau, travel expenses). The other authors declare no conflicts of interest. M.He. conflict of interest with Merck Serono (advisory role, speakers' bureau, honoraria, travel expenses, research funding); MSD (advisory role, speakers' bureau, travel expenses, research funding); AstraZeneca (research funding); Novartis (research funding); BMS (advisory role, honoraria, speakers' bureau); Teva (travel expenses). The other authors declare no conflicts of interest.

\section{Author details}

'Department of Radiation Oncology, Universitätsklinikum Erlangen, Friedrich-Alexander-Universität Erlangen-Nürnberg, Universitätsstraße 27, 91054 Erlangen, Germany. ${ }^{2}$ Comprehensive Cancer Center Erlangen-EMN, Erlangen, Germany. Institute of Pathology, Universitätsklinikum Erlangen, Friedrich-Alexander-Universität Erlangen-Nürnberg, Erlangen, Germany. ${ }^{4}$ Department of Otolaryngology - Head \& Neck Surgery, Universitätsklinikum Erlangen, Friedrich-Alexander-Universität Erlangen-Nürnberg, Erlangen, Germany. ${ }^{5}$ Department of Oncology, The Second Affiliated Hospital of Zunyi Medical University, Zunyi, China.

Received: 25 November 2020 Accepted: 28 February 2021

Published online: 24 March 2021

\section{References}

1. Weinmann SC, Pisetsky DS. Mechanisms of immune-related adverse events during the treatment of cancer with immune checkpoint inhibitors. Rheumatology (Oxford). 2019. https://doi.org/10.1093//heumatology/kez308.

2. Pardoll DM. The blockade of immune checkpoints in cancer immunotherapy. Nat Rev Cancer. 2012. https://doi.org/10.1038/nrc3239.

3. Xia L, Liu Y, Wang Y. PD-1/PD-L1 blockade therapy in advanced non-smallcell lung Cancer: current status and future directions. Oncologist. 2019. https://doi.org/10.1634/theoncologist.2019-IO-S1-s05.

4. Hecht M, Büttner-Herold M, Erlenbach-Wünsch K, Haderlein M, Croner R, Grützmann R, et al. PD-L1 is upregulated by radiochemotherapy in rectal adenocarcinoma patients and associated with a favourable prognosis. Eur J Cancer. 2016. https://doi.org/10.1016/j.ejca.2016.06.015.

5. Tsuchiya T, Someya M, Takada Y, Hasegawa T, Kitagawa M, Fukushima Y, et al. Association between radiotherapy-induced alteration of programmed death ligand 1 and survival in patients with uterine cervical cancer undergoing preoperative radiotherapy. Strahlenther Onkol. 2020. https://doi. org/10.1007/s00066-019-01571-1.

6. Derer A, Spiljar M, Bäumler M, Hecht M, Fietkau R, Frey B, Gaipl US. Chemoradiation increases PD-L1 expression in certain melanoma and Glioblastoma cells. Front Immunol. 2016. https:/doi.org/10.3389/fimmu.201 6.00610 .

7. Stenzinger A, Allen JD, Maas J, Stewart MD, Merino DM, Wempe MM, Dietel M. Tumor mutational burden standardization initiatives: recommendations for consistent tumor mutational burden assessment in clinical samples to guide immunotherapy treatment decisions. Genes Chromosom Cancer. 2019. https://doi.org/10.1002/gcc.22733.

8. Hecht M, Gostian AO, Eckstein M, Rutzner S, von der Grün J, Illmer T, et al. Safety and efficacy of single cycle induction treatment with cisplatin/ docetaxel/ durvalumab/tremelimumab in locally advanced HNSCC: first results of CheckRad-CD8. J ImmunoTher Cancer. 2020. https://doi.org/10.113 6/jitc-2020-001378

9. Sandigursky S, Mor A. Immune-related adverse events in Cancer patients treated with immune checkpoint inhibitors. Curr Rheumatol Rep. 2018. https://doi.org/10.1007/s11926-018-0770-0.

10. Haanen JBAG, Carbonnel F, Robert C, Kerr KM, Peters S, Larkin J, Jordan K. Management of toxicities from immunotherapy: ESMO clinical practice guidelines for diagnosis, treatment and follow-up. Ann Oncol. 2017. https:// doi.org/10.1093/annonc/mdx225.
11. Krause M. Management immunologischer Nebenwirkungen von Patienten, die mit Immun-Checkpoint-Inhibitoren behandelt werden: ASCO Clinical Practice Guideline Summary: Strahlentherapie und Onkologie: Organ der Deutschen Rontgengesellschaft [et al]; 2019. https://doi.org/10.1007/s00066019-01436-7.

12. Brahmer JR, Lacchetti C, Schneider BJ, Atkins MB, Brassil KJ, Caterino JM, et al. Management of Immune-Related Adverse Events in patients treated with immune checkpoint inhibitor therapy: American Society of Clinical Oncology clinical practice guideline. J Clin Oncol Off J Am Soc Clin Oncol. 2018. https://doi.org/10.1200/JCO.2017.77.6385.

13. Das $\mathrm{S}$, Johnson DB. Immune-related adverse events and anti-tumor efficacy of immune checkpoint inhibitors. J ImmunoTher Cancer. 2019. https://doi. org/10.1186/s40425-019-0805-8.

14. Haratani K, Hayashi H, Chiba Y, Kudo K, Yonesaka K, Kato R, et al. Association of Immune-Related Adverse Events with Nivolumab Efficacy in non-smallcell lung Cancer. JAMA Oncol. 2018. https://doi.org/10.1001/jamaoncol.201 7.2925 .

15. Ricciuti B, Genova C, de Giglio A, Bassanelli M, Dal Bello MG, Metro G, et al. Impact of immune-related adverse events on survival in patients with advanced non-small cell lung cancer treated with nivolumab: long-term outcomes from a multi-institutional analysis. J Cancer Res Clin Oncol. 2019. https://doi.org/10.1007/s00432-018-2805-3.

16. Schweizer C, Schubert P, Rutzner S, Eckstein M, Haderlein M, Lettmaier S, et al. Prospective evaluation of the prognostic value of immune-related adverse events in patients with non-melanoma solid tumour treated with PD-1/PD-L1 inhibitors alone and in combination with radiotherapy. Eur J Cancer. 2020. https://doi.org/10.1016/j.ejca.2020.09.001.

17. Eggermont AMM, Kicinski M, Blank CU, Mandala M, Long GV, Atkinson V, et al. Association between immune-related adverse events and recurrencefree survival among patients with stage III melanoma randomized to receive Pembrolizumab or placebo: a secondary analysis of a randomized clinical trial. JAMA Oncol. 2020. https://doi.org/10.1001/jamaoncol.2019.5570.

18. Hall ET, Singhal S, Dickerson J, Gabster B, Wong H-N, Aslakson RA, Schapira L. Patient-reported outcomes for Cancer patients receiving checkpoint inhibitors: opportunities for palliative care-a systematic review. J Pain Symptom Manag. 2019. https://doi.org/10.1016/j.jpainsymman.2019.03.015.

19. Basch E, Jia X, Heller G, Barz A, Sit L, Fruscione M, et al. Adverse symptom event reporting by patients vs clinicians: relationships with clinical outcomes. J Natl Cancer Inst. 2009. https://doi.org/10.1093/jnci/djp386.

20. Committee for Medicinal Products for Human Use. Keytruda, INNpembrolizumab. Eur Med Agency. 2020; https://www.ema.europa.eu/en/ documents/product-information/keytruda-epar-product-information_en.pdf. Accessed 23 Nov 2020.

21. Schubert P, Rutzner S, Eckstein M, Frey B, Schweizer C, Haderlein M, et al. Prospective evaluation of all-lesion versus single-lesion radiotherapy in combination with PD-1/PD-L1 immune checkpoint inhibitors. Front Oncol. 2020. https://doi.org/10.3389/fonc.2020.576643.

22. Hader M, Frey B, Fietkau R, Hecht M, Gaipl US. Immune biological rationales for the design of combined radio- and immunotherapies. Cancer Immunol Immunother. 2020. https://doi.org/10.1007/s00262-019-02460-3.

23. Teufel A, Zhan T, Härtel N, Bornschein J, Ebert MP, Schulte N. Management of immune related adverse events induced by immune checkpoint inhibition. Cancer Lett. 2019. https://doi.org/10.1016/..canlet.2019.04.018.

24. Atkinson TM, Ryan SJ, Bennett AV, Stover AM, Saracino RM, Rogak L, et al. The association between clinician-based common terminology criteria for adverse events (CTCAE) and patient-reported outcomes (PRO): a systematic review. Support Care Cancer. 2016. https://doi.org/10.1007/s00520-016-3297-9.

25. Basch E, Reeve BB, Mitchell SA, Clauser SB, Minasian LM, Dueck AC, et al. Development of the National Cancer Institute's patient-reported outcomes version of the common terminology criteria for adverse events (PRO-CTCA E). J Natl Cancer Inst. 2014. https://doi.org/10.1093/jnci/dju244.

26. Dueck AC, Mendoza TR, Mitchell SA, Reeve BB, Castro KM, Rogak LJ, et al. Validity and reliability of the US National Cancer Institute's patient-reported outcomes version of the common terminology criteria for adverse events (PRO-CTCAE). JAMA Oncol. 2015. https://doi.org/10.1 001/jamaoncol.2015.2639.

27. Voudouri D, Nikolaou V, Laschos K, Charpidou A, Soupos N, Triantafyllopoulou I, et al. Anti-PD1/PDL1 induced psoriasis. Curr Probl Cancer. 2017. https://doi.org/10.1016/j.currproblcancer.2017.10.003.

28. Belum VR, Benhuri B, Postow MA, Hellmann MD, Lesokhin AM, Segal NH, et al. Characterisation and management of dermatologic adverse events to 
agents targeting the PD-1 receptor. Eur J Cancer. 2016. https://doi.org/10.1 016/j.ejca.2016.02.010

29. Chang L-S, Barroso-Sousa R, Tolaney SM, Hodi FS, Kaiser UB, Min L. Endocrine Toxicity of Cancer Immunotherapy Targeting Immune Checkpoints. Endocr Rev. 2019. https://doi.org/10.1210/er.2018-00006.

30. Shivaji UN, Jeffery L, Gui X, Smith SCL, Ahmad OF, Akbar A, et al. Immune checkpoint inhibitor-associated gastrointestinal and hepatic adverse events and their management. Ther Adv Gastroenterol. 2019. https://doi.org/10.11 77/1756284819884196.

31. Ladak K, Bass AR. Checkpoint inhibitor-associated autoimmunity. Best Pract Res Clin Rheumatol. 2018. https://doi.org/10.1016/j.berh.2019.03.009.

32. Suresh $\mathrm{K}$, Naidoo J, Lin CT, Danoff S. Immune checkpoint immunotherapy for non-small cell lung Cancer: benefits and pulmonary toxicities. Chest. 2018. https://doi.org/10.1016/j.chest.2018.08.1048.

33. Nishino M, Giobbie-Hurder A, Hatabu H, Ramaiya NH, Hodi FS. Incidence of programmed cell death 1 inhibitor-related pneumonitis in patients with advanced Cancer: a systematic review and meta-analysis. JAMA Oncoogyl. https://doi.org/10.1001/jamaoncol.2016.2453.

34. Möhn N, Beutel G, Gutzmer R, Ivanyi P, Satzger I, Skripuletz T. Neurological immune related adverse events associated with Nivolumab, Ipilimumab, and Pembrolizumab therapy-review of the literature and future outlook. J Clin Med. 2019. https://doi.org/10.3390/jcm8111777.

35. Murakami N, Motwani S, Riella LV. Renal complications of immune checkpoint blockade. Curr Probl Cancer. 2017. https://doi.org/10.1016/j. currproblcancer.2016.12.004.

36. Jörling M, Rutzner S, Hecht M, Fietkau R, Distel LV. Deterioration of healthrelated quality of life scores under treatment predicts longer survival. Biomed Res Int. 2020. https://doi.org/10.1155/2020/3565238.

\section{Publisher's Note}

Springer Nature remains neutral with regard to jurisdictional claims in published maps and institutional affiliations.

Ready to submit your research? Choose BMC and benefit from:

- fast, convenient online submission

- thorough peer review by experienced researchers in your field

- rapid publication on acceptance

- support for research data, including large and complex data types

- gold Open Access which fosters wider collaboration and increased citations

- maximum visibility for your research: over $100 \mathrm{M}$ website views per year

At $\mathrm{BMC}$, research is always in progress.

Learn more biomedcentral.com/submissions 